\title{
A REPRESENTAÇÃO SOCIAL DA 'OUTRA INFÂNCIA' NO CONTEXTO DE OITOCENTOS E PARTE DE NOVECENTOS EM PORTUGAL
}

\section{The social representation of 'other childhood' in the context of eight hundred and part of nine hundred in Portugal}

\author{
Ernesto Candeias Martins - Escola Superior de Educação/ Instituto Politécnico de \\ Castelo Branco/Portugal
}

\begin{abstract}
RESUMO: Abordamos a representação social da infância portuguesa, mas especificamente a 'Outra infância', aquela que estava à margem da escolarização e normalização social da época e, por isso, necessitada de proteção, assistência e educação. $\mathrm{O}$ arco histórico de análise é o século XIX e parte do XX, norteado pelos seguintes objetivos: analisar a representação social da infância nas vertentes médico-assistencial higienista e na da infração ou desviação social; compreender os processos de proteção, de assistência socioeducativa ou de correção. A representação social, daquela infância relacionava-se com as suas situações sociais e condições de conflito a que estava submetida, pelo facto de viver na rua, e com as formas de relação com o mundo social, o que implicava a sua diferenciação com as ditas normais. A metodologia argumentativa é de índole histórico-documental, fenomenológica (fenómeno a 'outra infância') e hermenêutica. A imagem da infância foi influenciada por várias ciências, a partir finais do séc. XX e pelas políticas sociais, que culminou com dispositivos de proteção, de assistência, de institucionalização terminando no direito tutelar de menores (iniciado em 1911) e, principalmente nos direitos da criança, no séc. XX. O estudo pretende dar contributos à História [social] da Infância em Portugal, inserindo-os também na História [social] da Educação. Com este olhar, discurso e objeto de estudo, poderemos enriquecer aqueles campos da História, já que se trata de um tema de certa atualização socio histórica e cultural, relativo aquele campo disciplinar da 'Outra infância' como um novo objeto de investigação na nova história (Children Studies).
\end{abstract}

Palavras-chave: Dispositivo médico-pedagógico. Dispositivo jurídico-social. Outra iinfância. Proteção. Representação social.

ABSTRACT: We approached the social representation of Portuguese childhood, but specifically the 'Other childhood', the one that was on the margins of the schooling and social normalization of the time and, therefore, in need of protection, assistance and education. The historical arc of analysis is the nineteenth century and part of the 20th century, guided by the following objectives: To analyze the social representation of childhood in the medical-care-hygienist and in the aspects of infraction or social deviation; Understand the processes of protection, socio-educational assistance or correction. The social representation of that childhood was related to its social situations and conflict conditions to which it was subjected, by living on the street, and with the forms of relationship with the social world, which implied its differentiation with the socalled normal ones. The argumentative methodology is historical-documentary, phenomenological (phenomenon to 'other childhood') and hermeneutics. The image of childhood was influenced by several sciences, from the end of the century. XX and social policies, which culminated in provisions of protection, assistance, institutionalization 
ending in the right of guardianship of minors (started in 1911) and, mainly in the rights of the child, in the 19th century. The study aims to contribute to the [Social] History of Childhood in Portugal, also inserting them into the [Social] History of Education. With this look, discourse and object of study, we can enrich those fields of history, since it is a theme of a certain sociohistorical and cultural updating, related to that disciplinary field of 'Another childhood' as a new object of investigation in the new history (Children Studies).

Keywords: Another childhood. Social representation. Protection. Medical-pedagogical device. Legal-social provision.

\section{INTRODUÇÃO}

A criança e a sua infância são objetos de estudos e de investigações de várias ciências, convertendo-os em centro de políticas, práticas e análises conceptuais, a partir da Modernidade (DELGADO, 1998). É na família, na escola e no meio envolvente ou nos espaços comunitários, onde a criança se converte em objeto de conhecimento, de intervenção médico-pedagógica e socioeducativa e de políticas sociais e assistenciais. A preocupação com a infância em oitocentos esteve relacionada ao projeto de normalização da sociedade liberal, que indicava em crescimento desordenado de crianças (pobres, mendigas, abandonadas e vadias) fruto das situações de pobreza, miséria e de pauperismo, devido aos problemas sociais advindos de séculos anteriores. A expansão desordenada das cidades criou novas necessidades de organização social em que o Estado, associado aos contributos de várias ciências, sobretudo o saber médico-higienista, procurou respostas de prevenção e intervenção sanitária e assistencial, mas na prática foi mais uma função de policiamento que de assistência pública. Nesta ótica as crianças, os seres mais vulneráveis nestes cenários de flagelo social, mereceram respostas sociais, principalmente as pobres, mendigas, abandonadas, vadias ou as desvalidas.

Os condicionalismos sob os quais essas crianças estiveram submetidas na sua vivência de infância teve como consequência o surgimento de dispositivos ou medidas de índole jurídico-penal, assistenciais, profiláticas, médicas, higiene social/escolar, pedagógicas e psicológicas, etc., vinculada a uma determinada 'cultura de infância' em cada época, em que a imagem de si mesma era vista pelos adultos. Desde uma vertente assistencial e higienista até ao encerramento em asilos preventivos e de correção, passando por dispositivos jurídicos de proteção, essa 'Outra infância' teve reformas sociais com o objetivo de aliviar a consciência de uma sociedade ameaçada com a sua

Educação, Psicologia e Interfaces, Volume 4, Número 3, p. 1-17, Julho/Setembro, 2020.

ISSN: 2594-5343. DOI: 10.37444/issn-2594-5343.v4i3.270 
A representação social da 'Outra Infância' no contexto de Oitocentos e parte de Novecentos em Portugal

presença. A sua análise historiográfica permite-nos encontrar características dominantes que refletem diferentes formas e modos de ambivalência, nessa heteronímia de infância: da liberdade à subordinação (coação); da tutela ao controlo social; do apoio médicopedagógico e/ou psicopedagógico à submissão de internamento; do acolhimento assistencial aos modelos de correção e/ou reeducação.

O nosso estudo é de teor histórico-documental, fenomenológico e hermenêutico sobre a infância portuguesa, mas não a que teve uma escolarização e normatização social normal, nem uma vida familiar adequada à sua educação, mas sim aquela 'Outra Infância' (designação utilizada no texto), que por diversas situações e condições adversas ao seu normal crescimento, pelas carências (pobreza, miséria) e dificuldades familiares, maustratos e imoralidades, conflitos sociais, etc., (SOARES, 2001) encontrava-se à margem dessa normalização imposta pela sociedade e, daí cair no abandono, desamparo, mendicidade, marginalidade, exploração (trabalho infantil), vadiagem ou simplesmente desvalida, na definição da época (DICIONÁRIO DA LÍNGUA PORTUGUESA, 1927). Este tipo de infância necessitou de dispositivos de assistência, de proteção e de (re)educação, de modo a regenerar-se e/ou reeducar-se para a sociedade. Norteia a nossa argumentação, elencada no século XIX e parte do XX, nos seguintes objetivos: analisar a construção social dessa infância no âmbito médico-assistencialista e higienista; compreender as medidas destinadas à infância infratora e vitimizada, que devido à sua desviação social causava delitos.

A nossa pretensão é dar um contributo à História [Social] da Infância (abandonada, desvalida e delinquente) em Portugal, inserindo-a na História [Social] da Educação. Com novos olhares, discursos e objetos de estudo podemos enriquecer aqueles campos da História. De facto, trata-se de um tema de interesse socio-histórico, inserido naqueles campos disciplinares de abordagem à 'Outra infância', como novo objeto de investigação (BECCHI \& JULIA, 1998), na nova história (Children Studies)

\section{A INFÂNCIA CENTRO DE INTERESSE CIENTÍFICO E HISTORIOGRÁFICO}

No nosso périplo cronológico consideramos que, nos séculos XVI-XVII, foram tempos de afirmação da criança e dos cuidados que lhe eram devidos (vestuário, brinquedos, objetos diversos), tendo surgido no séc. XVIII um leque publicações

Educação, Psicologia e Interfaces, Volume 4, Número 3, p. 1-17, Julho/Setembro, 2020.

ISSN: 2594-5343. DOI: 10.37444/issn-2594-5343.v4i3.270 
(tratados, ensaios, obras literárias) que alertaram para esses cuidados especiais. ' $O$ Emílio’ de Rousseau constitui a baliza da tendência naturalista da criança como um ser bom, inocente e carente afetividade. A sua educação passa a ser uma aposta no futuro (DELGADO, 1998). Em Portugal surge obras com matérias relacionadas com a criança, p.e. as de Ribeiro Sanches 'Cartas sobre a Educação da Mocidade' (ABREU, 2013). Assistimos à emergência de discursos, inseridos no marco ideológico vigente nos finais do Antigo Regime, preocupados com os cuidados que devem ser concedidos à criança, principalmente os oriundos da medicina (preventiva), higienismo, eugenismo, puericultura, paidologia, etc., sob o ponto de vista da proteção social, saúde, higiene e educação. Considera-se a infância como um grupo distinto, definido pela idade, cuja análise exigia o conhecimento das condições estruturais em que se insere, tendo em conta as suas especificidades e as relações entre adulto-criança (CHARTIER, 2002). Demorou muito até que a ideia de infância fosse reconhecida como uma caraterística, como uma especificidade, própria da criança que a diferenciava do adulto. Segundo G. Agamben (2008) há uma modernidade para a infância e para os elementos que a constituem, numa relação 'infância-história'. Por isso, existe uma experiência particular sobre o tempo de infância que só cabe ao mundo moderno (criança como sujeito), o qual gerou um modelo próprio (criança burguesa), não estendido às outras infâncias (estigmatização). A configuração dessas infâncias diferenciadas (tipologias) (distintas da escolarizada e normal - a burguesa) provocou uma abundante produção científica e cultural (MARTINS, 2002).

Nas teses clássicas de Ariès (1987), sobre o surgimento da infância moderna, considera-se que a família e escola eram e são os lugares de socialização, onde se desenvolve de modo diferenciado e se reconhece o estatuto da criança. Enquanto a família é o lugar privado onde surge o sentimento afetivo, de relações de amor e de pertença familiar, a escola é o âmbito da aprendizagem, da moralização e normalização (JAMES \& PROUT, 1990). Nesta visão moderna considerava-se as novas práticas socioeducativas as causadoras das mudanças nas relações paternais e filiais, circunscrevendo as crianças à órbita da governabilidade da família e/ou da escola (CORSARO, 1997). No âmbito da socialização a infância molda-se àquele modelo de família/escola, sem desaparecer as práticas socioculturais relativas aos setores populares. Surgem, então, três dispositivos, nessa transição do antigo ao novo regime familiar: a moralização; a normalização; o

Educação, Psicologia e Interfaces, Volume 4, Número 3, p. 1-17, Julho/Setembro, 2020.

ISSN: 2594-5343. DOI: 10.37444/issn-2594-5343.v4i3.270 
A representação social da 'Outra Infância' no contexto de Oitocentos e parte de Novecentos em Portugal

contrato tutelar entre Estado-Família (instituições de acolhimento, p.e.: hospícios, hospitais, orfanatos, colégios, asilos).

As reflexões acerca da historicidade da infância (ARIÈS, 1988) e a coexistência de vários tipos de representações e práticas no seio da sociedade, fez prevalecer uma sobre a outra (p.e. a normal sobre a anormal), por motivos culturais e sociais, nem sempre fácil de distinguir. Por isso, o estudo da infância, na perspetiva histórica, implica questionamento de conceções e compreensão das infâncias em cada momento e lugar (este como lugar social), isto é, a criança como sujeito social, cultural e histórico (CORDERO, 2012).

$\mathrm{Na}$ verdade, a construção da categoria de 'infância' implicou o surgimento de conhecimentos e discursos de várias ciências, que reforçam a existência de um 'estatuto de menoridade' específico separado dos adultos. Por isso, o direito tutelar de menores, a partir de 1911, substitui os códigos penais, o discurso (psico)pedagógico legitima a caraterização da criança como um ser carente de razão, necessitando de educação e disciplina, o discurso médico e higienista preocupa-se pela saúde e higiene no crescimento infantojuvenil. É a própria noção de natureza infantil que faz surgir ciências como a paidologia, pedologia ou psicologia evolutiva e a psicotecnia (testes), que definem e regulem o seu desenvolvimento e com discursos, conceitos e técnicas de regulação da vida das crianças. É um facto que as preocupações sobre a 'Outra infância' fizeram reagir esse conjunto de ciências, desde a medicina (psiquiatria, pediatria, puericultura, higienismo), a pedologia e as jurídico-sociais (direito, criminologia, sociologia) na procura de medidas assistenciais e de proteção e, ainda, criação de instituições de acolhimento, assistência e correção ou (re) educação, pautando-se numa orientação baseada na neutralidade e no estabelecimento de padrões hegemónicos, universais e humanitários (filantropos, caritativos, beneficência) (ROCHA \& FERREIRA, 1995). O objeto dessa preocupação foi a criança, sem distinção de idade. Assim, surgem as reformas sociais na modernidade, que contribuíram para a construção e inserção social daquelas 'Outras Infâncias'. Podemos dizer que a infância recebe essa construção social conforme os contextos, espaços, circunstâncias e a cultura em que viveu e a influenciou. Qualquer revisão dessas perspetivas, antigas e recentes, sobre a infância e/ou a 'Outra infância“ revela-se um paradoxo constante, expressa por várias conceções.

Educação, Psicologia e Interfaces, Volume 4, Número 3, p. 1-17, Julho/Setembro, 2020.

ISSN: 2594-5343. DOI: 10.37444/issn-2594-5343.v4i3.270 


\section{A REPRESENTAÇÃO SOCIAL SOBRE A INFÂNCIA NA MODERNIDADE}

No âmbito das discussões teóricas de 'infância' e 'representação social', a primeira tem a sua definição clássica em De Mause (1982) que procurou a reivindicação dessa etapa nas tarefas dos historiadores, demonstrando as modificações da infância na perspetiva histórico-psicogenética das relações pais-filhos/crianças. Daí que De Mause (1982) se refira ao infanticídio como imagem da Antiguidade, depois ao abandono, seguindo as relações de ambivalente pais-filhos, entrando o 'infante' na vida afetiva (séc. XIV-XVII) e, depois no séc. XVIII a relação de 'intrusão' com a projeção perigosa da criança, passando ao vínculo da socialização (séc. XIX e meados do XX) nessas relações pais-filhos. Essa evolução promoveu a aproximação ao cânon das relações entre adultos e crianças pela história.

Por outro lado, a sociologia moderna aborda a problemática da infância na história, demonstrando as transformações nas relações 'pais-filhos', como sendo o resultado do processo de civilização a que a sociedade, de cada época, se submeteu. Esta relação assente num conjunto de 'cânones' específicos e socialmente condicionados determinou esse momento da infância como isolado dos adultos. Mesmo submetidas à crítica, respetivamente a perspetiva romântica e valorização experiencial da infância de $\mathrm{Ph}$. Ariès (1987) e a perspetiva psicogenética de Mause (1982), haverá que ter em conta as condições socio-genéticas, na identificação das estruturas nos processos históricos. Já L. Gaitán (2006), no contexto da sociologia contemporânea, trata a visibilidade das crianças como atores sociais, sujeitos de direitos, de tal modo que a infância é vista como parte da estrutura social. O mundo da criança é definido pelos adultos, gerando-se relações assimétricas entre eles, mas não reconhecem aquela como potencial humano (BECCHI; JULIA, 1998). A infância ('in-fancia' do latim 'in-fale', que não fala) foi entendida como uma abstração concetual construída, contendo especificidades históricas, sociais, culturais e educativas, desenvolvidas como etapas. Assim, o papel dos pais/família com as crianças é o de agente socializador primário (escola é o secundário), na sua responsabilidade com elas, mesmo com oscilações entre as queridas ou recusadas. Por isso, a infância mereceu análises das teorias evolutivas e da socialização, sendo uma etapa de inculcação de valores e formas de conduta aceites socialmente. Estas teorias fortaleceram as ideias sobre as crianças como seres dependentes, moldáveis e controláveis

Educação, Psicologia e Interfaces, Volume 4, Número 3, p. 1-17, Julho/Setembro, 2020.

ISSN: 2594-5343. DOI: 10.37444/issn-2594-5343.v4i3.270 
A representação social da 'Outra Infância' no contexto de Oitocentos e parte de Novecentos em Portugal

A representação social da infância intervém no cuidado e proteção às crianças (pautas culturais e históricas). A criança é o produto-efeito do processo de subjetivação (tempo de ser criança), no qual intervém uma representação social designada por infância. Isto explica o porquê das crianças variam segundo a época e cultura, pois o ser criança dependerá o que cada sociedade a entenda como tal (CORDERO, 2012). As representações sociais não são imutáveis, mudam com a história e, por isso, mudam os seus efeitos. No âmbito da História da Infância e da Educação a representação social da infância sofreu um processo curioso que vai desde o tipo de infância burguesa a outra infância que ocupava espaços e vivia experiências diferentes ao longo da história e, ainda ao uso da infância na história implicando um discurso hegemónico onde a infância representada apresenta experiências e situações diversas. No caso de De Mause (1982) estudou as práticas de criança em várias épocas concluindo que a história das crianças está cheia de crueldades (castigos, maus-tratos) até ao séc. XVII

Em termos sociológicos a 'representação' apresenta diferentes discussões, desde a sociologia clássica à perspetiva Durkheim, relacionado com 'representações sociais' (vínculo entre representações coletivas e a inserção na sociedade) e 'consciência coletiva' (crenças, sentimentos comuns, valores), ou seja, aquele sociólogo francês estabelece que categorias do conhecimento humano são adquiridas no processo de socialização e aprendizagem do indivíduo (DENZIN, 1997). É curioso que M. Weber introduz o debate das representações sociais no âmbito da ação social, em que o ator orienta o seu comportamento ao comportamento do 'Outro (s), associando-lhe o '[...] sentido de' (ideal, mental e representação) (GAITÁN, 2006, p. 17), que no caso da infância implica designação de representações sociais (elaborações do sentido comum na forma de conhecer o seu quotidiano). R. Chartier (2002), apoiando-se em De Mause e Durkheim, considera as representações coletivas como perceções que dão sentido à nossa realidade e à forma de nos relacionar com o mundo social, isto é, a representação associa-se aos processos cognitivos/psíquicos de perceção e objetivação.

A construção social da infância explica-se a partir da contextualização histórica dos argumentos que conformam as diferentes representações construídas pelos adultos. O espírito da modernidade, assente no progresso contínuo e nas ciências, faz surgir a infância, como origem das caraterísticas do adulto racional e, por isso, desde o nascimento impõe-se à criança um trajeto com finalidades, sequenciada em etapas (infância), segundo

Educação, Psicologia e Interfaces, Volume 4, Número 3, p. 1-17, Julho/Setembro, 2020.

ISSN: 2594-5343. DOI: 10.37444/issn-2594-5343.v4i3.270 
o padrão cronológico. Assim, a historiografia sobre a infância e a sua educação interpreta a criança no contexto narrativo das suas experiências. Mas, no âmbito institucional, essa representação permite desvelar perceções para com o grupo social, já que as instituições infantojuvenis se compõem de indivíduos com propósitos que interiorizam e se justificam no processo de regeneração/reeducação. Ou seja, o pensamento institucional de internamento permitia a classificação social dos próprios internados (CHARTIER, 2002).

No caso das crianças reais, historicamente situadas (contexto, época), estão sujeitas à violência de uma forma contemporânea de racionalidade científica que se reproduziu à custa das suas diferenças, para lá do contexto da vida social localizada. A normalidade das crianças era analisada em termos das normas provenientes da paidologia e/ou pedologia (psicologia do desenvolvimento) nas escolas (normalização escolar). Algumas assunções da teoria da socialização e dessa pedologia da época influenciaram a conceptualização quotidiana e de senso comum sobre a infância, dita normal. São formas que deram origem à diversidade de perspetivas, imagens e representações da criança, segundo os diferentes mundos sociais (e culturais) teóricos onde habitavam, pois, como diz Denzin (1997, p. 189) "[...] A infância é habitualmente vista como um período de felicidade despreocupada e desorganizada".

Ora bem a modernidade contribuiu com um corpus de atributos para o conceito de infância, p.e.: o tempo linear, evolutivo e predizível da infância como etapa para o futuro; a escolarização das crianças e os cuidados a ter; criação do mundo infantil separado do mundo adulto (fronteiras); e perceção da criança como incapaz de fazer certas coisas e daí a proibição de alguns trabalhos. Contudo, a aceleração das mudanças científicas e tecnológicas, associado ao processo de mundialização cultural deu um tipo de sociedade, com o progresso e as novas estruturas sociais, fez surgir desigualdades e exclusão social, com efeitos nas crianças. Os condicionalismos sob os quais a criança esteve submetida, desde da modernidade, promoveu reformas sociais (políticas) com medidas de proteção e assistência, de índole jurídico-legal, médico-social (pediatria, higienismo), sociopedagógica, psicológica, etc. vinculando-se a uma determinada 'cultura de infância' em cada época, com uma imagem de si mesma vista pelos adultos. Deste modo, a história [social] da infância e da sua educação/formação é, portanto, uma história da heteronomia da(s) infância(s) no tempo histórico. A sua análise permite encontrar conceções e características dominantes que reflectem diferentes formas e modos históricos de 
A representação social da 'Outra Infância' no contexto de Oitocentos e parte de Novecentos em Portugal

ambivalência: da liberdade e da subordinação (coação), da tutela e do controle social, do apoio sociopedagógico/assistencial e da submissão (SÁNCHEZ, 2010).

$\mathrm{O}$ 'Século da Criança' produziu um grande desenvolvimento teórico-conceptual à volta das crianças, p.e. os contributos do Movimento da Escola Nova, cognitivismo e a psicanálise, de tal forma que elas se incorporam ao imaginário social, modificando as pautas de cuidado e de criança (novas figuras infantis com novas problemáticas, como a criança consumidora) até à Declaração Universal dos Direitos da Criança, em 1958. A criança da rua, a vadia, abandonada, delinquente e a que trabalha precocemente vivem de maneira diferente a sua infância em relação ao tempo social construído pelas crianças da Modernidade.

\section{A IMAGEM DA INFÂNCIA NA VERTENTE MÉDICO-SOCIAL E HIGIENISTA}

A pobreza e o pauperismo, devido à conjuntura social da época, originavam elevados índices de infanticídio e expostos, sendo colmatada, em grande parte, pela uma missão das misericórdias, mas, por outro lado, não conseguia dar resposta social ao abandono infantil. Perante a elevada percentagem de crianças abandonadas e desvalidas foram-se criando no séc. XIX, vários estabelecimentos públicos e privados, destinados a recolher indivíduos e crianças de famílias desfavorecidas, assumindo uma prática assistencial, associada a uma forte componente religiosa e filantrópica. Os médicos e os higienistas chocavam-se perante a descoberta de ghettos, situações e condições de muitas famílias (classes desfavorecidas, pobres, operárias) e das crianças, vitimas diretas ou indiretas dessa localização social. A saúde pública converteu-se numa questão social, que não podia estar dependente de filantropos e beneméritos, mas sim da consciencialização médico-sanitária e social (CORREIA, 1934).

Era comum encontrar crianças, nos centros populacionais, na situação de mendicidade, abandono, pobreza, vadiagem ou delinquência, apresentando o corpo e/ou o vestuário deplorável e imune. Os espetros dos rostos dessas 'Outras' crianças e das mulheres, nas várias cidades do país (Lisboa, Porto, Coimbra, Setúbal, etc.) eram adjetivados de magros, pálidos e macilentos, expressões famélicas do rosto, além de sujos e ranhosos, apresentando uma grande falta de higiene, desnutrição, andrajosas, franzinas, raquíticas e o corpo maculados e cheios de feridas (maus tratos). A imprensa da época é

Educação, Psicologia e Interfaces, Volume 4, Número 3, p. 1-17, Julho/Setembro, 2020.

ISSN: 2594-5343. DOI: 10.37444/issn-2594-5343.v4i3.270 
uma grande fonte de narratividade desses flagelos sociais existentes nesses bairros, especialmente as situações da infância autênticos andrajos. Os adultos vagabundos e mendigos que com ela convivia nas ruas, nos albergues e nas prisões levavam peças como o gibão ou o velho capote militar que alguns envergavam dia e de noite, calças rotas, remendadas e sujas; a boina proletária, os chapéus deformados e sovados pelo uso; os buracos e os remendos da roupa e abrigos, devido ao estrafego a que estavam sujeitos os indivíduos que os exibiam; o espectro da tuberculose (MARTINS, 2002). As mulheres, algumas tísicas, desnutridas e enfezadas, com as suas saias sujas de tons escuros, cobrindo-se com xailes, que serviam, simultaneamente, de cobertor aos filhos que se aninhavam junto ao peito, protegendo-os do frio, já para não falar das casas, onde viviam aglomerados de pessoas, como relata o Editorial O Século (Lisboa, 11/02/1922, p. 2) "Há casas de gente pela Alfama e por Alcântara, onde vivem seis e sete crianças em promiscuidade com parentes enfermos, sem agasalhos, sem roupa e sem ter que comer".

Esse espetro de crianças vadias, seminuas, numa promiscuidade com a terra e a lama, que ladeava as suas casas (becos, pátios, tugúrios, barracas, 'ilhas', choças, subterrâneos) acompanhando as mães ou pais, ajudando-os a reforçar as lamúrias e a segurarem no casaco dos transeuntes para obrigá-los a reparar no seu aspeto e obter a esmola pretendida. Para além do calçado, frequentemente inexistente nas crianças e nos adultos, apresentava-se muito gasto e esburacado. Essas crianças sem família ou pertencentes a famílias não normais, pobres e/ou numerosas alimentavam-se mal, chafurdavam nos lixos das ruas. Outras davam-se ao luxo de comerem caldo sem tempero, sardinha, batata e broa (SANTOS, 1938).

Perante estas situações a morbilidade, mortalidade, a natalidade, a imoralidade e os maus-tratos e outros comportamentos, etc. eram aspetos atribuídos a essas classes sociais proletárias, desfavorecidas, em pobreza, miséria e promiscuidade, com ambientes degradantes com perigosidade epidémica e endémica. Este cenário obrigou a medidas erigidas pelo higienismo, numa base de regulação pública e privada, que articulava a moralidade, regeneração e a ordem social, procurando evitar custos económicos e sociopolíticos desnecessários com a perda de vidas ou enfraquecimento da 'raça' (ROCHA; FERREIRA, 1995). A medicina e o médico higienista (social e escolar) atacavam as causas exteriores, numa preocupação pública de controlo sanitário-higiénico. Os médicos higienistas tinham como justificativa ideológica o fator genético e o 
A representação social da 'Outra Infância' no contexto de Oitocentos e parte de Novecentos em Portugal

casamento eugénico, como princípios para a saúde dos filhos. Esta mentalidade profilática e eugenista orientaram o sentido da prevenção.

O sentido científico e instrumental da medicina (social) assentou numa racionalidade experimental, que pretendia conhecer as causas (influência positivista) e debelar os efeitos, ou seja encontrar o remédio à doença, não só corporal, mas também social de certos coletivos, em especial as crianças, de tal modo que se confronta com realidades humanas e sociais insuspeitáveis. A partir de meados de oitocentos progrediuse no progresso de muitas ciências o que conferiu, no caso da medicina, uma autonomia e legitimidade na salvação dos corpos, da nação e da raça (eugenismo). $O$ desenvolvimento das ciências médicas na base da identificação de novos objetos (doenças epidémicas, como a tuberculose, difterias, diarreias/enterites, varicela, infeções pulmonares, raquitismo, etc.) intentava evitar a mortalidade infantil, reveladores de uma natureza social e cultural das suas causas e previam a ameaça e perversidade dos seus efeitos (a sífilis, alcoolismo, etc.) (CORREIA, 1934).

$\mathrm{Na}$ verdade, o movimento higienista pressionou o Estado para a necessidade de assistir, ensinar e corrigir aquelas famílias e crianças, principalmente a infância desvalida, marcado por preconceitos morais e religiosos. Neste contexto, a assistência aos desvalidos, vai mais além da assistência caritativa e piedosa de séculos anteriores, para incidir no controlo social pelo Estado. A caridade confrontada com a nova realidade económica e social, de acordo com os valores higienistas e fundamentada nos valores científicos, tinha como objetivo a ação e prevenção da desordem. Não é por acaso que na agenda da 1. ${ }^{a}$ República a criança foi considerada a base fundamental da construção da Nação, no âmbito da proteção e educação.

Paulatinamente, a higiene (social) interligou-se à saúde, às condições físicocorporais, ao banho, à alimentação, à prevenção, à profilaxia e terapêutica social. As situações de contágio e desinfeção ganharam um sentido importante na sociedade de finais do séc. XIX até meados do séc. XX, tal como a salubridade urbana, as condições sanitárias das classes operárias. Assim, se fundam institutos de higiene, a regulação do Instituto de Higiene Ricardo Jorge no seu papel de higiene social nos bairros operários afastados das zonas burgueses (Decretos de 28/12/1899 e 24/12/1901), “[...] revelando uma ação de diferenciação social (estatutário, físico, morfológico, demográfico, sanitário) na prevenção de epidemias e pestes" (ROCHA; FERREIRA, 1995, p. 77). A higiene 
escolar também foi uma outra medida expansiva a todas as condições das escolas, para um normal processo instrutivo das crianças.

Ao nível de eventos científicos e publicações houve uma dedicação pela criança e pelo âmbito materno-infantil, surgindo outras áreas da medicina (pediatria, puericultura) com um papel importante no reconhecimento da problemática da infância na vertente assistencial e higiénica e de intervenção nas situações de alimentação e amamentação, doenças (infeto) contagiosas (sífilis, tuberculose), prostituição, higiene no trabalho, deficiências e debilidades congénitas, quicemas, infeções gastrointestinais e respiratórias, hereditariedade fisiológica, mortalidade infantil, etc. Todos estes aspetos os saberes médicos denunciavam, reclamava e perspetivavam medidas preventivas e de proteção social e assistencial à criança e à mãe ou soluções institucionais que recolhessem crianças. Ou seja, a emergência e consolidação dos novos saberes médicos permitiram proteger e prevenir a infância, incluindo a 'Outra infância' incluindo a institucionalizada em hospícios, recolhimentos, asilos, colégios, escolas de reforma, reformatórios, etc. $\mathrm{Na}$ verdade, ao ser acolhida e protegida em instituições essa infância ficava disciplinada nas suas práticas no forjamento do corpo e da sua higiene (alimentação, roupa, banhos, ginástica) (ROCHA \& FERREIRA, 1995). Deu-se, assim, uma inter-relação entre a condição biológica e a sociocultural, em termos de prevenção e proteção.

\section{A CONCEÇÃO DA INFÂNCIA VITIMIZADORA OU INFRATORA}

O quadro ideológico de oitocentos (liberalismo) marcado pelo progresso, pela industrialização, urbanização e emergência da classe operário fabricou um discurso em que a criança é retratada por vítima, de cruel quando não corrigida, um ser com tendência a desviação social, marginalização e delinquência. Muitos destes discursos científicos influenciados pela escola positivista (italiana e francesa), especialmente a de Lombroso, não apresentam uma imagem favorável da criança (vadio, gaiato, larápio, delinquente, criminoso). A imprensa e o fotojornalismo são fontes ilustrativas desses tipos de criança ou infância.

A ideia de que todas as crianças têm as mesmas oportunidades de vida na sua infância e que muitas delas são encarceradas ou caiem nas malhas da justiça ou em perigo de delinquir ou em desviação e marginalização social. Muitas destas dimensões inscrevem-se nos quadros da vadiagem, mendicidade, prostituição, conflitos sociais, 
A representação social da 'Outra Infância' no contexto de Oitocentos e parte de Novecentos em Portugal

delinquência e infração delitiva. De facto, são situações enquadradas dentro do problema social que implicava medidas jurídicas de proteção, assistência e (re)educação. Referirnos às crianças infratoras é remeter-nos ao conceito socialmente construído de delinquência, ligado a valores, normas e representações, que têm essa infância em relação à ordem social, com comportamentos diferenciados (tipologia de delinquentes: ocasionais, estatutários ou persistente/reincidente) (SOARES, 2001). Este fenómeno preocupante desde o séc. XIX, pela sua visibilidade social, foi motivo de dois modelos: modelo penitenciário (séc. XIX) assente na ideia da criança como culpada e da concetualização como adulto em miniatura; modelo de proteção (finais do séc. XIX) que está subjacente uma dimensão de criança como vítima (CUSSON, 2006). As iniciativas governamentais na proteção da infância infratora foram: Casa Pia de Lisboa (1780) para vadios desvalidos; Casas da Roda e hospícios (expostos, abandonadas); asilos para infância desvalida (a partir de 1834); Casa de Detenção e Correção de Lisboa (1871); Colónia Agrícola Correcional de Vila Fernando (1889); escolas de reforma (1911); reformatórios (1919); etc. (MARTINS, 2002; OLIVEIRA, 1929).

O movimento pós-filantrópico, a finais do século XIX, impõe uma nova conceção da criança vadia e delinquente não como culpada, mas sim como uma vítima de factores estruturais. Esta nova corrente considerava o menor transgressor (com menos de 16 anos) como uma vítima e, por essa razão, tinha comportamentos delitivos. Com efeito, o menor responsabilizado era considerado culpado, enquanto, no caso da criança vitima, a família e o meio envolvente eram designadas como responsáveis (OLIVEIRA, 1929). Assim, admitia-se tomar a cargo o menor e educá-lo e a sua 'má família' uma pedagogia de reconversão. Assim, surge o estatuto legal da criança culpada ao de criança vítima, nascendo a ideia da 'assistência educativa' em encarceramento, com programas (re) educativos que visava aconselhar a criança e a família. A área escolar e a médicopedagógica uniam-se na reabilitação do menor. Esta concepção de criança vítima foi sendo varrido nos inícios do século XX, devido ao domínio da psiquiatria infantojuvenil, no campo da desviação comportamental (nova noção de 'desvio'), passando-se a considerar 'inadaptada'. A psiquiatria, a paidologia e a pedologia preconizavam a adaptação ou a readaptação pedagógica institucional (SARMENTO, 2000).

Por conseguinte, no início de novecentos mudaram as intervenções/medidas jurídico-legais e assistenciais, passando a infância a ser cada vez menos encarada como

Educação, Psicologia e Interfaces, Volume 4, Número 3, p. 1-17, Julho/Setembro, 2020.

ISSN: 2594-5343. DOI: 10.37444/issn-2594-5343.v4i3.270 
culpada que é preciso punir, e cada vez mais como estado 'em risco', como vitima, sendo necessário protege-la, quer da sua família, quer do meio ou contexto em que vive (DEUSDADO, 1931). Assim, promulga-se o direito específico para a criança delinquente, abandonada, inadaptada, vadia, indisciplinada e 'em perigo moral' a Lei de Protecção à Infância, de 1911 e seguinte legislação (1919, 1925, 1936, 1938, 1962, etc.), com os mecanismos das Tutorias Centrais de Infância e os seus Refúgios em anexo, para diagnóstico e intervenção temporária. Com implementação do direito tutelar de menores a delinquência e a infância infratora constituíram um estado inocente e dependente que requeria cuidados, regeneração, educação e disciplina. As novas conceções reformistas resultantes dos campos dicotómicos das ciências jurídicas, psiquiatria, criminologia e pedagogia correcional contribuem para retirar atos menos positivos e penalmente condenáveis cometidos por crianças e jovens. Esta nova jurisprudência de menores propõe novos exames médico-pedagógicos e psiquiátricos (supera-se os antigos exames antropométricos) antes de definir o estatuto de uma criança ou jovem delinquente.

De facto, o menor delinquente ou com comportamentos antissociais é considerado como uma anomalia constitucional das tendências do individuo. O menor delinquente é um enfermo atingido por perversões precoces dos instintos (sociais). Na verdade, o instinto compreende se como uma tendência múltipla e variada, fixada pela hereditariedade (genética), reforçada pelos hábitos e pela educação recebida. Assim, o menor pervertido tinha afetado o instinto social. Com o impulso da psicanálise, os conceitos sobre a delinquência enriqueceram-se pondo a tónica no factor da afectividade. $\mathrm{O}$ afeto passa a ser uma noção primordial e explicativa a vida quotidiana individual e social, associada ao papel do meio na constituição de normas, pela qual o indivíduo responde aos influxos do meio. As perturbações afetivas nascem na infância, no meio familiar e são preponderantes nos efeitos dessas carências no desenvolvimento da delinquência e desviação juvenil (SANTOS, 1938).

\section{RETENDO IDEIAS (IN) CONCLUSIVAS}

Pretendemos abordar a represenção social da 'Outra Infância' aquela que sendo vadia, pobre, mendiga, abandonada ou desvalida e, ainda a infratora ou delinquente tiveram medidas de proteção, assistência e ducação no séc. XIX e parte do XX em Portugal, seja de intervenção institucional ou não. Os ideais da 'salvação da criança' 
A representação social da 'Outra Infância' no contexto de Oitocentos e parte de Novecentos em Portugal

disseminaram-se no âmbito político e na economia daqueles séculos, justificando-se nas ciências médicas (médico-sanitário e higienismo), nas ciências jurídicas e psicopedagógicas, para impor medidas de protecção e prevenção, que no fundo formaram esparsas iniciativas, a maior parte delas privadas/religiosas de índole assistencial, filantrópico e de beneficência, seja em apoios, seja em acolhimento em internato. Na entrada do Século da Criança, a criação de organismos estatais orientados à infância, manifestaram algumas acções concretas em prol da criança, apesar da grande disseminação de um ideário higienista e de profilaxia social de combate à pobreza/miséria, doenças sociais e analfabetismo. Todas essas intervenções socioeducativas, públicas e privadas, de política social de assistência/educação à infância caracterizaram-se por justificações científicas médico-higienistas e jurídicas, positivistas e até idealistas, voltada para a imputação da culpa ora do indivíduo, ora da família, dirigindo aos menores programas e políticas especiais (direito tutelar de menores). Essas acções pretenderam a educação popular e instrução, especilamente os hábitos, os costumes e os valores nas classes e famílias mais desprotegidas e vulneráveis, com medidas de profilaxia social, higiene social, saúde, assistência materno-infantil, etc. e a criação de instituições de internato para a infância, exercendo uma acção paralela e até substituta da família, submetendo-a aos padrões sociais, morais, cívicos e sanitários considerados necessários para o seu desenvolvimento.

$\mathrm{Na}$ organização social dos serviços de assistência à infância, desde séc. XX, adaptou-se uma intencionalidade socioeducativa e de regeneração moral, presente nas instituições jurídicas de menores (tutorias de infância, tribunais de menores e de família), medidas médico-sanitárias e de (re)educação que foram substituindo a tradição hospitalar e carcerária por Casas de Detenção e Correcção, de recolhimentos, colégios por asilos em oitocentos (CORREIA, 1934). É verdade que essas instituições de internação tiveram inicialmente uma postura correcional (autoritária, repressiva) e de internação, depois mais paternalista e bondosa (tutelar), já na 1. ${ }^{a}$ República. Os homens da 'ciência' naqueles centúrios foram os detentores da 'verdade', sendo capazes de sugerir medidas e dispositivos de intervenção, contribuindo para distribuição social sob controlo e coesão social, na perspetiva da 'melhoria da raça', da saúde e assistência social (pública), do patriotismo, do civismo e valores humanos. De facto, a escola, tal como as instituições de 
assistência e educação à 'Outra Infância' tiveram pretensões semelhantes e pautaram-se pelos mesmos princípios científico-pedagógicos.

\section{REFERÊNCIAS BIBLIOGRÁFICAS}

ABREU, L. Pina Manique: Un reformador no Portugal das Luzes. Lisboa: Gradiva

AGAMBEN, G. Infância e História: Destruição da experiência e origen da história. Belo Horizonte: Editora UFMG, 2008

ARIÈS, Ph. A criança e a vida familiar no Antigo Regime. Lisboa : Relógio d'Água, 1988

BECCHI, E. \& JULIA, D. (ed.). Histoirede l’ enfance en Occident. Paris, Seuil, 1998

CHARTIER, R. El Mundo como representación. Barcelona: Ed. Gedisa, 2002

CORDERO, M. Towards an Emancipatory Discourse of Children's Rights. The

International Journal of Children's Rights, 20 (3), 2012, p. 365-421.

CORREIA, F.S. Problemas de Higiene e Puericultura. Coimbra: Imp. Univ. Coimbra, 1934

CORSARO, W. A. The Sociology of Childhood. Thousand Oaks: Pine Forge Press, 1997

CUSSON, M. Criminologia. Lisboa: Casa das Letras, 2006

De MAUSE, L. Historia de la Infancia. Madrid: Ed. Alianza, 1982.

DELGADO, B. Historia de la Infancia. Barcelona: Ed. Ariel, 1998

DENZIN, N. Childhood socialization. S. Francisco: Jossey-Bass, 1997

DEUSDADO, M.A. F. A onda do Crime: etiología e profilaxia. Lisboa: João d'Araújo Moraes, L. da, 1931

DICIONÁRIO DA LÍNGUA PORTUGUESA (1927). Dicionário Etimológico, Prosódico e Ortográfico (24. ${ }^{\text {a }}$ ed.). Rio de Janeiro: Liv. Francisco Alves; Lisboa: Liv. Aillaund e Bertrand

GAITÁN, L. Sociología de la infancia: Nuevas Perspectivas. Madrid: Ed. Síntesis, 2006

JAMES, A. \& PROUT, A. (orgs). Constructing and Reconstructing Childhood. Basingstoke: Falmer, 1990

Educação, Psicologia e Interfaces, Volume 4, Número 3, p. 1-17, Julho/Setembro, 2020.

ISSN: 2594-5343. DOI: 10.37444/issn-2594-5343.v4i3.270 
A representação social da 'Outra Infância' no contexto de Oitocentos e parte de Novecentos em Portugal

MARTINS, E.C. 'As Reformas Sociais e a Protecção da Criança Marginalizada (estudo histórico do Séc. XIX a meados do séc. XX) '. Infância \& Juventude, no 3, 2002, p. 55-93.

OLIVEIRA, A. Proteção Moral e Jurídica à Infância. Lisboa: Tip. Reformatório Central de Lisboa Pe. António de Oliveira, 1929

ROCHA, C. \& FERREIRA, M. Alguns contributos para a compreensão da construção médico-social da infância em Portugal (1820-1950). Educação, Sociedade e Cultura (Univ. Porto), n. ${ }^{\circ}$ 2, 1995, p. 59-90.

SÁNCHEZ, J. 'Puerilizado y adulterado: representaciones institucionales de la infancia'. Universitas, Revista de Ciencias Sociales y Humanas, 13, 2010, p. 95-130.

SANTOS, Ary dos. Como nascem, como vivem e como morrem os criminosos. Lisboa: Livraria Clássica Ed., 1938

SARMENTO, M. J. A Infância: Paradigmas, Correntes e Perspectivas. Braga: Instituto de Estudos da Criança - Universidade do Minho, 2000

SOARES, N. F. Outras Crianças...A situação social das crianças atendidas numa comissão de Proteção de Menores. Braga: Centro de Estudos da Criança/Univ. do Minho, 2001

\section{Credenciais da/os autora/es}

MARTINS, Ernesto Candeias - Doutor em Ciências da Educação C/Título de Agregado à Universidade (ULisboa-IE) na área da Educação/História da Educação, investigador no CeiED da ULHT e docente no ensino superior politécnico -Instituto Politécnico de Castelo Branco (Portugal). Orcid: 0000-0003-4841-1215. E-mail: ernesto@ipcb.pt

Endereço para correspondência: Ernesto candeias Martins - Escola Superior de Educação, Instituto Politécnico de Castelo Branbco. Rua Prof. Faria de Vasconcelos, 6000 - 262 (Portugal)

Como citar este artigo (Formato ABNT): MARTINS, Ernesto C. A representação social da 'Outra Infância' no contexto de Oitocentos e parte de Novecentos em Portugal. Educação, Psicologia e Interfaces, v.4, n.3, p. 1-17, 2020. Doi: 10.37444/issn-25945343.v4i3.270

Recebido: $27 / 03 / 2020$.

Aceito: 02/05/2020.

Educação, Psicologia e Interfaces, Volume 4, Número 3, p. 1-17, Julho/Setembro, 2020.

ISSN: 2594-5343. DOI: 10.37444/issn-2594-5343.v4i3.270 